\title{
Population based study of hospitalised fall related injuries in older people
}

\author{
N M Peel, D J Kassulke, R J McClure
}

Injury Prevention 2002;8:280-283

See end of article for authors' affiliations

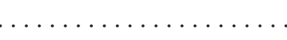

Correspondence to: Associate Professor Roderick McClure, Injury Prevention and Control (Australia) Ltd, School of Population Health, University of Queensland Medical School, Herston QLD 4006, Australia;

r.mcclure@sph.uq.edu.au

\begin{abstract}
Objective: This study aimed to identify the distribution of fall related injury in older people hospitalised for acute treatment of injury, in order to direct priorities for prevention.

Setting: A follow up study was conducted in the Brisbane Metropolitan Region of Australia during 1998.

Methods: Medical records of patients aged 65 years and over hospitalised with a fall related injury were reviewed. Demographic and injury data were analysed and injury rates calculated using census data as the denominator for the population at risk.

Results: From age 65, hospitalised fall related injury rates increased exponentially for both males and females, with age adjusted incidence rates twice as high in women than men. Fractures accounted for $89 \%$ of admissions, with over half being to the hip. Males were significantly more likely than females to have fractured their skull, face, or ribs $(p<0.01)$. While females were significantly more likely than males to have fractured their upper or lower limbs $(p<0.01)$, the difference between proportions of males and females fracturing their hip was not significant. Males were more likely than females $(p<0.01)$ to have fall related head injuries (13\% of admissions). Compared with hip fractures, head injuries contributed significantly to the burden of injury in terms of severity, need for intensive care, and excess mortality.

Conclusions: The frequency and impact of hip fractures warrants continued emphasis in falls program interventions for both males and females to prevent this injury. However, interventions that go beyond measures to slow and protect against bone loss are also needed to prevent fall related head injuries.
\end{abstract}

njury is recognised as an important contributor to the global burden of disease, ${ }^{1}$ and initiatives in injury prevention and control are a public health priority in many countries. ${ }^{2-4}$ Specific groups targeted for preventive interventions are those aged 65 and over who suffer injuries, particularly from falls, which cause substantial morbidity, mortality, and health care costs. ${ }^{5}$

Characterisation of the nature and extent of fall related injuries in the older population is needed in order to direct priorities for prevention and evaluate the effectiveness of falls prevention programs in reducing the incidence of serious injury. Fractures of the hip are a common fall related injury documented in a number of epidemiological reviews ${ }^{67}$ Intervention programs aimed at preventing such fractures include use of hip protectors, exercise, dietary supplementation, and medications to prevent or treat osteoporosis. ${ }^{8}$ Less well documented are other injuries to older people, such as head injuries, which may also contribute significantly to death and disability from falls. ${ }^{10}$

Studies have established reliable estimates of the incidence of fall related injury events in population based settings ${ }^{11-14}$; however, detailed analysis of injury by type and body region is not readily available. This study aimed to identify injury distribution by type and body part in older people from a circumscribed population admitted to hospital for acute treatment of a fall related injury.

\section{METHODS}

\section{Study design and setting}

A follow up study was conducted in Brisbane, a subtropical metropolitan city on the eastern seaboard of Australia, over a 12 month period between 1 January and 31 December 1998.

\section{Ethical considerations}

The study was approved by the University of Queensland ethical review committee for research involving human partici- pants and by the hospital ethics committee in accordance with the National Health and Medical Research Council's Guidelines.

\section{Participants}

The study population included all people aged 65 years and over resident in the Greater Brisbane Region during the study period. Australian Bureau of Statistics 1998 census data by age, sex, and statistical local area were used to define the population at risk. ${ }^{15}$ Study participants included all those from the population at risk who were admitted for more than 24 hours to any of the 14 hospitals in the region for acute treatment of a fall related injury. For the purposes of this study, injury was defined as any condition able to be coded to the International Classification of Diseases, Clinical Modification (ICD9$\mathrm{CM}$ ) nature of injury $(\mathrm{N})$ codes between 800.0 and 995.0 and a fall was an external cause able to be coded to an ICD9-CM E code between 880 and 888 . Patients who died as a result of their injury before 24 hours had elapsed were also included in the dataset.

\section{Variables and research process}

Data collected from the medical records of all study participants included the following variables: date of birth, sex, address; date, mechanism and place of injury; admission date; operations; days in the intensive care unit; discharge destination; injury type and severity, encoded using the abbreviated injury scale (AIS) ${ }^{16}$ and the injury severity score. ${ }^{17}$

Abbreviations: AIS, abbreviated injury scale; $\mathrm{Cl}$, confidence interval; ICD9-CM, International Classification of Diseases, Clinical Modification 
Table 1 Age and sex specific rates of fall related injury admissions/1000 population

\begin{tabular}{|c|c|c|c|c|c|}
\hline Age group & No* & $\begin{array}{l}\text { Population at } \\
\text { risk }\end{array}$ & Incidence rate & Rate ratio & $95 \% \mathrm{Cl}$ \\
\hline \multicolumn{6}{|l|}{ Male } \\
\hline $65-74$ & 109 & 42013 & 2.59 & $1 \dagger$ & \\
\hline $75-84$ & 200 & 22931 & 8.72 & 3.36 & 2.66 to 4.24 \\
\hline$\geqslant 85$ & 120 & 5198 & 23.09 & 8.90 & 6.88 to 11.51 \\
\hline \multicolumn{6}{|l|}{ Female } \\
\hline $65-74$ & 245 & 48406 & 5.06 & $1 \dagger$ & \\
\hline $75-84$ & 562 & 34425 & 16.33 & 3.23 & 2.78 to 3.75 \\
\hline$\geqslant 85$ & 518 & 12318 & 42.05 & 8.31 & 7.15 to 9.66 \\
\hline
\end{tabular}

Fractures of the hip were identified by AIS codes 851808.3 , $851810.3,851812.3$, and 851818.3. Any injury to the cranium, face, or neck (including cervical spine) was categorised as a head injury. A subset of head injuries-intracranial injurieswas defined by AIS codes 113000.6, 115099.9, 115299.9, 140202.5 to 140799.3 , and 160202.2 to 161000.2 .

\section{Analysis}

Age and sex specific injury admission rates were calculated using persons admitted with fall related injury as the numerator and census data as the denominator for population at risk. Frequency distributions examined the range of injuries by place of injury, type of injury, and body region affected. Differences for males and females were examined in univariate analysis. For injuries to the hip and head, differences in outcomes were examined in univariate analysis using $\chi^{2}$ tests for categorical data and $t$ tests for continuous data, with $p$ values less than 0.05 being taken as the level of statistical significance. The outcome measures used were injury severity, intensive care unit treatment, whether operations were performed, length of stay in hospital, and whether the patient was discharged home, transferred to further care, or died in hospital as a result of injury. The independent effects of age, sex, and injury severity were examined in logistic regression models, using survival/death in hospital as the dependent variable. SPSS Statistical Package was used for data analysis.

\section{RESULTS}

The number of injury admissions in 1998 to people aged 15 years and over was 6506, with 2090 (32\%) being to people aged 65 years and over. Of the 2090 injury admissions to older people, $1754(84 \%)$ recorded a fall as the mechanism of injury. Age and sex specific rates of fall related injury admissions are shown in table 1. The incidence rate for females compared with males remained consistently higher (between 1.8 and 2.0 times) at each age group.

The case fatality rate was $5.2 \%$, with 91 deaths in hospital as a result of a fall related injury. In a logistic regression model to test the effects of age, sex, and injury severity on death in hospital, increasing age (odds ratio $1.06,95 \%$ confidence interval (CI) 1.02 to 1.09 ) and higher injury severity scores (odds ratio $1.18,95 \%$ CI 1.13 to 1.23 ) were significant independent predictors.

Of the 1754 cases ( 429 males, 1325 females) admitted with a fall related injury, 969 (55.2\%) occurred at home while 477 $(27.2 \%)$ were in a residential institution at the time of injury. As approximately $6 \%$ of the Queensland population 65 years and over is in residential care, ${ }^{18}$ fall related injuries requiring hospitalisation are disproportionately high for institutionalised residents when compared to community dwellers. While institutionalised fall related injury cases were significantly older than non-institutionalised fallers (mean age of 85.1 years compared with 79.8 years respectively), there was no
Table 2 Type of injury and body region affected; values are number $(\%)$

\begin{tabular}{|c|c|c|c|}
\hline Type of injury & $\begin{array}{l}\text { Males* } \\
(n=427 \dagger)\end{array}$ & $\begin{array}{l}\text { Females* } \\
(n=1323+)\end{array}$ & $\begin{array}{l}\text { Significance } \\
\text { (p value } \ddagger \text { ) }\end{array}$ \\
\hline \multicolumn{4}{|l|}{ Fractures } \\
\hline Skull & $11(2.6)$ & $11(0.8)$ & 0.005 \\
\hline Face & $12(2.8)$ & $13(1.0)$ & 0.006 \\
\hline Spine & $20(4.7)$ & $39(2.9)$ & NS \\
\hline Ribs & $30(7.0)$ & $24(1.8)$ & 0.000 \\
\hline Upper limb & $44(10.3)$ & $218(16.5)$ & 0.002 \\
\hline Lower limb & $281(65.8)$ & $967(73.1)$ & 0.004 \\
\hline Hip & 192 (45.0) & 655 (49.5) & NS \\
\hline \multicolumn{4}{|c|}{ Joint dislocations/sprains } \\
\hline Spine & $5(1.2)$ & $7(0.5)$ & NS \\
\hline Upper limb & $13(3.0)$ & $23(1.7)$ & NS \\
\hline Lower limb & $12(2.8)$ & $55(4.2)$ & NS \\
\hline \multicolumn{4}{|c|}{ Superficial wounds§ } \\
\hline Head & 53 (12.4) & $130(9.8)$ & NS \\
\hline Trunk & $9(2.1)$ & $9(0.7)$ & 0.011 \\
\hline Upper limb & $46(10.8)$ & $77(5.8)$ & 0.000 \\
\hline Lower limb & $29(6.8)$ & $83(6.3)$ & NS \\
\hline Multiple sites & $12(2.8)$ & $27(2.0)$ & NS \\
\hline Head injuries & $74(17.3)$ & $159(12.0)$ & 0.005 \\
\hline Intracranial & $29(6.8)$ & $49(3.7)$ & 0.007 \\
\hline \multicolumn{4}{|c|}{$\begin{array}{l}\text { *Columns represent no of cases and \% of gender group. The unit of } \\
\text { analysis is the injury so that a person with multiple injuries may be } \\
\text { counted more than once. } \\
\text { There were four cases (two males, two females) with missing injury } \\
\text { data. } \\
\text { †Differences for nature of injury between males and females were } \\
\text { examined using } \chi^{2} \text { tests. } \\
\S S \text { Superficial wounds include abrasions, contusions, and lacerations to } \\
\text { the skin. } \\
\text { NS }=\text { not significant at the } p<0.05 \text { level. }\end{array}$} \\
\hline
\end{tabular}

significant difference in sex distribution between institutional and non-institutional fall related injury admissions.

The 1754 cases presented with 2689 fall related injuries, an average of 1.5 injuries per fall event (injury data were missing for four cases). Main types of injury and body regions affected for males and females are shown in table 2. Fractures occurred in $1566(89 \%)$ of fall related injury admissions. Males were significantly more likely than females to have fractured their skull, face, or ribs $(p<0.01)$. Of hospitalised fall related injuries to the extremities, females were significantly more likely than males to have fractured their upper or lower limbs $(p<0.01)$. However, the difference between proportions of males and females fracturing their hip was not significant.

Of the body regions affected, there were 1558 cases with injury to the extremities and 233 with head injuries, of which 78 were intracranial injury. Males were significantly more likely than females to have suffered head injuries, including intracranial injury $(\mathrm{p}<0.01)$.

A comparison of hip fracture and intracranial injury cases is shown in table 3 . When adjusting for age and sex, cases from 
Table 3 Comparison of hip fracture and intracranial injury*; values are number (\%) unless otherwise stated

\begin{tabular}{|c|c|c|c|}
\hline & $\begin{array}{l}\text { Hip fracture } \\
(n=847)\end{array}$ & $\begin{array}{l}\text { Intracranial injury } \\
(n=78)\end{array}$ & $\begin{array}{l}\text { Significance (p } \\
\text { valuef) }\end{array}$ \\
\hline Mean age (years) & 82.3 & 80.4 & 0.03 \\
\hline \multicolumn{4}{|l|}{ Place of injury } \\
\hline Home & $417(49.2)$ & $44(56.4)$ & \multirow{4}{*}{0.0004} \\
\hline Residential institution & $320(37.8)$ & $14(17.9)$ & \\
\hline Other & $84(9.9)$ & 13 (16.7) & \\
\hline Unknown & $26(3.1)$ & $7(9.0)$ & \\
\hline Mean injury severity score & 9.07 & 17.79 & 0.0000 \\
\hline \multicolumn{4}{|l|}{ Procedures } \\
\hline Operations & $780(92.4) \ddagger$ & $21(26.9)$ & 0.0000 \\
\hline Intensive care unit treatment & $21(2.5) \ddagger$ & $28(35.9)$ & 0.0000 \\
\hline \multicolumn{4}{|l|}{ Outcomes } \\
\hline Death in hospital & $49(5.8)$ & $19(24.4)$ & \multirow{3}{*}{0.0000} \\
\hline Transferred for further treatment & $176(20.8)$ & 15 (19.2) & \\
\hline Discharged & $621(73.4) \S$ & $44(56.4)$ & \\
\hline Mean length of stay for survivors (days) & 17.85 & 15.14 & NS \\
\hline $\begin{array}{l}\text { *There were no cases with both hip fract } \\
\text { †Demographic and injury outcome differ } \\
\text { injury were examined using } \chi^{2} \text { tests for } c \\
\text { †Three cases had data missing. } \\
\S \text { One case had data missing. }\end{array}$ & $\begin{array}{l}\text { racranial inju } \\
\text { eeen persons } \\
\text { data and } t \text { te }\end{array}$ & $\begin{array}{l}\text { ing a hip fracture or } \\
\text { continuous data. }\end{array}$ & intracranial \\
\hline
\end{tabular}

institutions were $2.6(2.1-3.3)$ times more likely to be admitted with a fractured hip than non-institutional cases, but there was no significant association between institutionalisation and admission for a fall related head injury.

In comparison to cases with hip fracture, intracranial injury cases were significantly younger (mean age $80.4 v 82.3$ years), were more severe (injury severity score mean $17.79 v 9.07$ ), and more likely to die in hospital as a result of the injury $(24.4 \% v 5.8 \%)$. While intracranial injury was more likely to require admission to intensive care $(35.9 \%$ v $2.5 \%)$, cases were less likely to require operative procedures $(26.9 \% v 92.4 \%)$.

\section{DISCUSSION}

The rate of fall related injury admissions increased exponentially with age for both males and females, and age adjusted incidence rates were approximately twice as high in women than in men. This is consistent with previous studies, ${ }^{12} 1319$ which have shown similar age and sex associations with fall rates for injury requiring medical attention. Age related increase in frailty and disability is thought to account for the increased fall related injury rates with age and would also account for the disproportionately high rate of fall related injuries in residential care settings, ${ }^{11}{ }^{20}$ despite the increased levels of supervision in institutional care.

The major fall related injury was a fracture $(89 \%$ of admissions) with over half (54\%) of such cases having a fracture of the hip. Of fall related injury admissions from residential care settings, 67\% sustained a hip fracture. In contrast, Luukinen et al found that, in institutions, the highest proportion of serious injuries (defined as fractures, dislocations, and soft tissue injuries requiring suturing) were to the head. ${ }^{11}$

The frequency of hip fractures warrants continued emphasis of falls programs to prevent this injury. Hip protectors appear to reduce the risk of sustaining hip fracture within selected high risk populations such as those in residential care. ${ }^{21}$ Injuries to the head are also a frequently occurring fall related injury. Intracranial injuries, compared with hip fractures, contribute significantly to the burden of injury in terms of severity, need for intensive care, and excess mortality. While no interventions have been developed to protect against fall related head injury in this population, the primary prevention of falls should remain the first priority.

The difference in nature and site of injury between males and females may be explained by differences in the mechanism and activity being undertaken at the time of the fall and host risk factors such as comorbidities. Despite the lack of such data in this study, the sex differences in injury patterns may assist the focus of injury prevention interventions. For example, the fact that no significant sex differences in hip fracture rates were found in this study, suggests that interventions such as the use of hip protectors and the prevention and treatment of osteoporosis should be aimed at both males and females. The high rate of head injuries particularly among men suggests the need for interventions that go beyond measures to slow and protect against bone loss.

\section{Limitations}

This study represents a population based incidence of fall related injury severe enough to warrant hospitalisation. This assumption depends on the accuracy of both numerator and denominator. All hospitals in the area, except one small private hospital, were included in the data collection. Fewer than $5 \%$ of the study sample had residential postcodes outside the census district. The assumption for the numerator is that those admitted from outside the area would be balanced by those from the catchment area injured and treated elsewhere. The use of census data for the denominator to calculate rates in defined populations is in accord with methodology used previously.

While the focus of the study was on the nature of injury and body part injured, it would have been of additional interest to describe the distribution of injury characteristics with respect to causal mechanism. Unfortunately, the nature of the data was such that detailed circumstances of the injury event were not available.

The study criteria included all fall related deaths that occurred during prehospital (ambulance) care, emergency department treatment, or hospitalisation. A substudy of reliability of coding in this dataset showed good to excellent inter-rater reliability as measured by $\kappa$ for all variables discussed in this paper. ${ }^{22}$ Cases of deaths from falls where there was no postmortem contact with the hospital system were not included. However, it is thought the numbers would be small and unlikely to affect the conclusions of the study.

\section{CONCLUSIONS}

Until more is known about preventing fall related injuries, the focus of interventions continues to be prevention of falls themselves. There is now sufficient evidence that falls prevention programs targeting both intrinsic and environmental risk 


\section{Key points}

- This study establishes a population based incidence of hospitalised fall related injury in older people.

- The study focus is to describe detailed distribution of fall related injury by body part and nature of injury, and to discriminate sex differences in patterns of injury.

- Hospitalised fall related injury rates for older people increased with age, and rates were twice as high in women than men.

- Fractures, particularly to the hip, were the main injury sustained.

- Admissions for fall related hip fractures were disproportionately high for institutionalised compared with noninstitutionalised residents, after adjusting for age and sex.

- Males were more likely than females to be hospitalised with fall related head injuries, which also contributed significantly to the burden of injury in this age group.

- Until there is more evidence for the effective prevention of fall related injuries, the primary prevention of falls should remain the first priority.

factors of individual patients are effective in community based settings. ${ }^{23}$ Less is known about effective falls prevention interventions in institutional settings. However, specifically for those who provide care in residential institutions there is a need to raise awareness of the potential for, and sequelae of, fall related injuries in their elderly clients.

This study has contributed to the already extensive falls literature by establishing a population based incidence of fall related injury requiring hospitalisation, describing detailed distribution of injury by body part and nature of injury, and discriminating sex differences in patterns of injury. Given that the sociodemographic characteristics of urban centres throughout Australia are essentially similar, ${ }^{24}$ it would be reasonable to assume that the results for Brisbane would be representative of other large urban cities in Australia.

\section{Authors' affiliations}

N M Peel, D J Kassulke, R J McClure, School of Population Health, University of Queensland, Queensland, Australia

\section{REFERENCES}

1 Murray CJ, Lopez AD. Mortality by cause for eight regions of the world: Global Burden of Disease Study. Lancet 1997;349:1269-76.

2 US Department of Health and Human Services. Healthy people 2010: understanding and improving health. 2nd Ed. Washington, DC: US Government Printing Office, 2000.
3 Secretary of State for Health. Saving lives: our healthier nation. London: The Stationery Office, 1999

4 Strategic Injury Prevention Partnership, Department of Health and Aged Care. National injury prevention plan: priorities for 2001-2003. Canberra, ACT: Commonwealth of Australia, 2001.

5 National Injury Prevention Advisory Council. Directions in injury prevention report 1: research needs. Canberra, ACT: Commonwealth Department of Health and Aged Care, 1999.

6 Kannus P, Parkkari J, Sievanen H, et al. Epidemiology of hip fractures. Bone 1996; 18:S57-63

7 Rose S, Maffulli N. Hip fractures. An epidemiological review. Bull Hosp Jt Dis 1999;58:197-201.

8 Kannus P, Parkkari J, Niemi S, et al. Prevention of hip fracture in elderly people with use of a hip protector. N Engl J Med 2000;343:1506-13.

9 Nagurney JT, Borczuk P, Thomas SH. Elderly patients with closed head trauma after a fall: mechanisms and outcomes. J Emerg Med 1998;16:709-13

10 Rakier A, Guilburd JN, Soustiel JF, et al. Head injuries in the elderly Brain Inj 1995;9:187-93.

11 Luukinen H, Koski K, Honkanen R, et al. Incidence of injury-causing falls among older adults by place of residence: a population-based study. $J$ Am Geriatr Soc 1995;43:871-6.

12 Sattin RW, Lambert Huber DA, DeVito CA, et al. The incidence of fall injury events among the elderly in a defined population. Am J Epidemiol 1990;131:1028-37.

13 Kingma J, Ten Duis HJ. Severity of injuries due to accidental fall across the life span: a retrospective hospital-based study. Percept Mot Skills 2000;90:62-72.

14 Kannus P, Parkkari J, Koskinen S, et al. Fall-induced injuries and deaths among older adults. JAMA 1999;281:1895-9.

15 Australian Bureau of Statistics. Population by age and sex, Queensland. Cat No 3235.3. Canberra, ACT: Australian Bureau of Statistics, 1999.

16 Garthe E, States JD, Mango NK. Abbreviated injury scale unification: the case for a unified injury system for global use. J Trauma 1999:47:309-23.

17 Baker SP, O'Neill B, Haddon W, et al. The injury severity score: a method for describing patients with multiple injuries and evaluating emergency care. J Trauma 1974;14:187-96.

18 Australian Institute of Health and Welfare. Residential aged care in Australia: a statistical overview. Aged Care Statistical Series Report No 9. Canberra, ACT: Department of Health and Aged Care, 2001.

19 Scott VJ, Gallagher EM. Mortality and morbidity related to injuries from falls in British Columbia. Can J Public Health 1999;90:343-7.

20 Butler $M$, Norton R, Lee-Joe T, et al. The risks of hip fracture in older people from private homes and institutions. Age Ageing 1996;25:381-5.

21 Parker MJ, Gillespie LD, Gillespie WJ. Hip protectors for preventing hip fractures in the elderly (Cochrane Review). The Cochrane Library, Issue 2 2002. Oxford: Update Software.

22 Neale R, Rokkas P, McClure R. Reliability of injury coding in the Queensland Trauma Registry. Proceedings of the 5th National Conference on Injury Prevention and Control, 25-28 September, 2001; Warrnambool, Victoria, Australia. Warrnambool: Deakin University, 2001.

23 Gillespie LD, Gillespie WJ, Robertson MC, et al. Interventions for preventing falls in elderly people (Cochrane Review). The Cochrane Library, Issue 1, 2002. Oxford: Update Software.

24 Australian Bureau of Statistics. Social atlas series-census update. 15 August 1998 (available from: URL://www.abs.gov.au/ausstats). 